\title{
Análisis de los elementos de identidad de un espacio público. El caso del parque Juárez (Xalapa, México)
}

Carmen Egea-Jiménez. Universidad de Granada, Granada, España. José-Antonio Nieto-Calmaestra. Junta de Andalucía, Granada, España.

RESUMEN | Los espacios públicos forman parte de la ciudad, le imprimen calidad, son elementos de identidad, construyen la imagen que se tiene de ella. Algunos se conciben en el momento del planeamiento y otros tienen su origen en procesos de reorganización, resignificación y/o reutilización del espacio. A esta segunda situación corresponde el parque Juárez de Xalapa, al ubicarse en el espacio que ocupó el convento de Santo Domingo (1556), manteniendo desde su inauguración (1892) el carácter de lugar de ocio. El artículo analiza la identidad de este espacio, marcada por ser un lugar central con características particulares en cuanto a estructura y uso, que lo convierten en un indiscutible punto de referencia de la ciudad. La metodología seguida en el presente trabajo es de carácter cualitativo y se basa en la información recogida en trabajo de campo (cuaderno de campo y registros fotográficos) y el análisis de las opiniones compartidas en Google Maps.

PALABRAS ClAVE | espacio público, geografía social, imaginarios urbanos.

ABstract | Public spaces are part of the city, they print quality, they are elements of identity, they build the urban image. Some are conceived at the time of planning and others have their origin in processes of reorganization, resignification, andlor reuse of space. Juarez Park corresponds to the former, by locating in the space once occupied by the Convent of Santo Domingo (1556), and by maintaining its recreation character since its inauguration (1892). The article analyzes the identity of this space marked by being a central place with particular characteristics in terms of structure and use, which makes the park a reference in the city of Xalapa. The methodology uses a qualitative approach and is based on the collection of information in field work (field notebook and photographic records), and analysis of shared opinions in Google Maps.

KEYWORDs | public space, social geography, urban imaginary. 


\section{Introducción}

La bibliografía sobre el estudio de los espacios públicos en América Latina pone de manifiesto una fructífera producción científica en la región durante las dos primeras décadas del siglo xxi, en la que las dimensiones de análisis, los ejes temáticos y los tipos de espacios investigados dotan de una gran riqueza a este tema. En general, hay una tendencia a diferenciar entre un espacio público pensado desde el ámbito político, cuyos referentes están en la filosofía de Arendt (1958) y Habermas (1962), y un espacio público delimitado en el espacio-tiempo, que es el que se asume aquí: el espacio público caracterizado por ser de titularidad pública, de uso libre y gratuito, el que con estas características queda entre los espacios construidos. En relación con este segundo significado, si bien las definiciones pueden presentar matices, lo cierto es que parece haber consenso en reconocerle un sentido social: "el espacio público es el lugar y el medio a través del cual se legitiman la equidad, el respeto por el otro y la sociedad que se comunica" (Flores et al., 2004, p. 170), es una expresión de la ciudadanía: "donde la ciudad se da a conocer, donde se muestran sus (...) valores y aptitudes culturales, sociales y políticas de aquellos que lo habitan (...) cuanto más abierto esté a todos, más expresará la democratización política y social” (Hernández, 2005, p. 197), y goza de una clara vocación para la sociabilidad: "es una reunión de extraños inmersos en una territorialidad común (...) allí se asume su derecho a la espontaneidad, a la interacción voluntaria (...)" (García \& Coral, 2004, pp. 104-105). En definitiva, se puede considerar que los espacios públicos son "un excelente termómetro para determinar los grados de la integración social, los alcances de los sentidos de pertenencia, las capacidades de apropiación de lo público y los niveles de democracia obtenidos en un barrio, una zona o una ciudad" (Rizzo, 2010a, p. 9); un reflejo de la diversidad, donde es inevitable -consciente o inconscientemente- reconocerse en igualdad a las demás personas (Muñoz, 2007). Esto implica también que, desde el punto de vista metodológico, los contenidos del espacio público se analicen a través de determinadas dimensiones de análisis: la 'identidad del lugar', ligada al 'sentido del lugar', 'sentido de pertenencia' y/o 'apego al lugar', relacionada esta identidad-sentido con la 'apropiación' del lugar que surge de las 'prácticas cotidianas' y 'socioespaciales', de las cuales pueden surgir (o no) 'conflictos' por el 'control' del espacio, aunque el control también genera 'seguridad y confianza' (Cárdenas, 2017).

Si bien puede existir un consenso en todos estos elementos, el tratamiento metodológico, e incluso los aspectos por investigar, varían según el punto de vista teórico, reconociéndose dos enfoques en los que, a grandes rasgos, se inscriben las diferentes investigaciones. El primero es aquel que plantea la crisis del espacio público, relacionada con la proliferación de superficies comerciales como lugares de ocio-consumo, la multiplicación de urbanizaciones cercadas, la semiprivatización de espacios de titularidad pública, el aislamiento personal, el sentimiento de inseguridad, etcétera (Berroeta \& Vidal, 2012; Filipe \& Ramírez, 2016). Este discurso se ha enriquecido con el término "agorafobia" que, procedente de las ciencias de la salud, alude al miedo que se tiene a los espacios públicos por las actividades que se realizan y/o por la presencia de determinados colectivos (Vega, 2017; Vivas, 2006). En este 
primer enfoque es importante mencionar a Delgado (1999, 2007), cuyos trabajos en general entienden el espacio público como eminentemente conflictual, donde la sociabilidad aparece con vínculos frágiles, aunque es importante tener presente que su interés se centra en un espacio público concreto, la calle, que es, sin lugar a dudas, un espacio impredecible donde es fácil encontrar situaciones antagónicas.

En paralelo a este planteamiento está el enfoque del derecho a la ciudad y la ciudadanía, entroncado con la obra de Lefebvre (1967) y revitalizado por autores como Borja y Muxí (2001), Borja (2003) y Harvey (2013). Para Lefebvre (1967), el espacio es político, ideológico, dinámico y cambiante; resultado de múltiples prácticas cotidianas y socioespaciales, reconocido por su sentido dialéctico y la capacidad de la sociedad para transformarlo. Desde este planteamiento, Borja (2003) y Borja y Muxí (2001), señalan la necesidad de superar la visión pesimista consolidada, aceptada y practicada como consecuencia de las políticas neoliberales, visión que puede ser superada con la apropiación del espacio público como lugar de encuentro y reivindicación, teniendo en cuenta que no todas las ciudades ni todos los espacios públicos se caracterizan por idénticas problemáticas. Es necesario superar el término 'espacio público' como si se tratase de una dimensión espacial genérica, abordando ejes temáticos poco investigados, como "espacio cotidiano", "espacio de relaciones sociales", "espacios de juego", "espacios de recorrido diario". Tiempo atrás, Jacobs (1967) planteó una perspectiva más optimista que otros autores coetáneos, como Sennett (1977), criticando los procesos de renovación urbana descontextualizados de las formas cotidianas de habitar la ciudad, siendo valiosa su aportación en la gestión comunitaria y el diseńo de los espacios públicos para promover la sociabilidad y la interacción social. Estos aspectos aproximan esta autora a Gehl (2009, 2015), quien pone de manifiesto la importancia del diseńo urbano para facilitar, por una parte, los encuentros fortuitos o intencionados y la oportunidad de que un mismo espacio pueda ser compartido por personas diferentes; y por otra, para promover "la vida entre los edificios". En su obra de 2015, Gehl hace un recorrido por los aspectos propios de un espacio público de calidad, concluyendo que los doce identificados se agrupan en tres dimensiones de análisis: la protección, el confort y el disfrute del lugar.

Desde este enfoque se reconoce el espacio público -en un sentido amplio y desde una perspectiva teórico-espacial- como el lugar donde se forma y construye la ciudadanía (López, 2012; Salcedo, 2002). Así, la presente investigación se aproxima a este segundo enfoque en tanto el parque Juárez de Xalapa se analiza como un espacio público exitoso, "donde las personas se sienten cómodas compartiéndolo con desconocidos" (Petzold, 2017, p. 31), en un claro ejercicio de ciudadanía. Esta idea es la que conduce la bibliografía consultada y el mismo análisis de un 'espacio público central' que puede ser un ejemplo de los muchos que caracterizan a las ciudades de América Latina. También constituye una oportunidad para resarcir del imaginario la percepción que se tiene de las ciudades mexicanas como inseguras, peligrosas y violentas, o al menos mostrar el papel que desempeńan espacios públicos como el parque Juárez en tanto barómetros de convivencia, ciudadanía y paz. Se plantea así una perspectiva de cultura de paz en la que este lugar muestra su capacidad para 
la convivencia y el compartir, donde las personas se igualan en el uso del espacio haciendo cosas diferentes y ejerciendo el sentir ciudadano.

En general, las ciudades latinoamericanas cuentan en su trama urbana con un elemento bien diferenciado, la "plaza hispanoamericana" (Low, 2009) o "plaza fundacional” (Salazar, 2017), en ocasiones resultado del espacio ganado a construcciones religiosas en el proceso de desamortización y localizadas donde las ciudades tienen su origen: en el centro, la zona más dinámica del núcleo urbano por su multifuncionalidad y diversidad social. La plaza refuerza, así, el sentimiento de pertenencia al ser un espacio público "que da servicio a todos los ciudadanos y a toda la ciudad" (Delgadillo, 2011, p. 45); es un 'lugar histórico' delimitado por la escala temporal y espacial donde se concentran "las manifestaciones culturales de una civilización" (Gamboa, 2003, p. 13); guardián de la memoria colectiva donde "simbólicamente (...) se depositan los elementos que otorgan identidad a una cultura” (Salazar, 2017, p. 31). Una imagen heredada y conservada con la que es fácil identificarse (Ayala, 2015), pues resume muchos de los elementos materiales e inmateriales con los que se identifica la población (García, 2018). Estos elementos de identificación se construyen con prácticas cotidianas al usar el espacio para estar, permanecer, encontrarse y sociabilizar (Vivas, 2009); son espacios de confluencia y tránsito por su capacidad receptora, adonde se puede llegar desde muchos lugares y desde donde se puede partir a diferentes destinos (Del Valle, 2004), concebido en el imaginario como un punto de inflexión en la caminata urbana; y son indicadores de calidad de vida urbana por su capacidad para adaptarse a estándares de accesibilidad y de permanencia, las primeras características que definen un espacio público como tal (Gehl, 2015).

En este contexto se analiza un ámbito acotado espacialmente, el parque Juárez de la ciudad de Xalapa, resultado de su devenir histórico y de las prácticas socioespaciales cotidianas y periódicas que le han ido imprimiendo significado y valor. Estos tres elementos (tiempo, espacio y prácticas socioespaciales) actúan como dimensiones del análisis de su identidad de lugar y de "su forma de ser" (Gomes \& Ribeiro, 2018, p. 171). Por tanto, el artículo tiene como objetivo analizar cómo se comportan esos elementos/dimensiones de análisis para construir la identidad del parque Juárez. Esto supone concretar dos conceptos: el de espacio público y el de identidad del lugar. El espacio público es -como se ha expresado anteriormente- el que queda entre los edificios construidos, es de titularidad pública y de acceso libre y gratuito. No obstante, esta definición queda incompleta si no se considera a la comunidad que lo usa, y que se enriquece con los argumentos de Treviño (2013):

Son espacios públicos todos los espacios que facilitan la generación, mantenimiento y reproducción de la sociedad civil, del público en cualquiera de sus definiciones. (...) los espacios de co-visibilidad, reunión, negociación, reconocimiento de similitudes y tolerancia entre los individuos pertenecientes a distintos grupos (...) todos los lugares donde los individuos se juntan para conversar, compartir intereses comunes (...) y, ocasionalmente, influenciar la opinión pública o la política pública (...). La función principal del espacio público es propiciar deliberada o aleatoriamente ese encuentro. Por lo tanto, la esencia de las ciudades depende de la eficiencia de sus espacios públicos para propiciar el encuentro o el desencuentro. (p. 33) 
Respecto a la identidad de lugar, esta se conceptualiza como la dimensión que define la identidad personal del individuo en su relación con el medio físico a través de ideas, preferencias, valores, conductas, etcétera, influyendo esa experiencia espacial en los mismos individuos (Páramo, 2002); por otro lado, la identidad se construye y recrea "como una imagen dentro de la memoria que (...) permite identificarse con el pasado y el presente" (Gamboa, 2003, p. 13), siendo la experiencia espacial compartida entre usos y usuarias/os la que termina construyendo la identificación individual y colectiva (García, 2018). Este proceso es el que genera el sentido de lugar al dotar al espacio, considerado como un ente abstracto, de significado y valores - muchas veces- con carga afectiva, sentimental y emocional (Fu-Tuan, 1977; Lindón et al., 2006), lo cual reafirma aún más el sentido de pertenencia. En realidad, los conceptos de identidad de lugar, sentido de lugar y sentido de pertenencia están interrelacionados, siendo los segundos los que aludirían más en concreto a la experiencia espacial como constructora de la identidad, aunque el límite entre ambos no resulte muy nítido (Ortiz i Guitart, 2006). En cualquier caso, lo que sí es cierto es que el sentido de lugar fomenta la apropiación y responsabilidad de lo que allí sucede (Fu-Tuan, 1977), lo que abunda en el sentido de pertenencia e implica mayor participación y preocupación por su conservación.

\section{Metodología}

El presente análisis se basa en una metodología de carácter inductivo enfocada a conocer los elementos identificadores del parque Juárez a partir del sentido de lugar y de pertenencia de la población, que responde metodológicamente a los lineamientos de la Teoría Fundamentada; es decir, son los datos los que construyen la teoría, aunque sin olvidar los aportes bibliográficos. La información de partida es básicamente cualitativa: datos de carácter histórico, trabajo de campo y reseñas del lugar en Google Maps, que permiten analizar los elementos que dan identidad al parque: continuidad a lo largo de la historia y estructura espacial, factores básicos para entender las prácticas socioespaciales; y la percepción y valoración de las personas que lo visitan.

Desde la perspectiva histórica, se analiza la identidad del lugar como un espacio que a lo largo del tiempo se dota de significados y valores (Páramo, 2002), los cuales se mantienen a la vez que experimentan transformaciones. La documentación usada alude al contexto en que surge el parque y a los momentos en que se producen sus cambios más importantes, recogiéndose información de algunas páginas de internet y fotografías antiguas que se comparan con la situación actual.

El análisis de la estructura espacial se basa en la realización ex profeso de un plano del parque (Figura 7), sin el cual sería difícil entender sus características. La realización de este plano tiene como base el de OpenStreetMap, completado con información recabada durante el trabajo de campo.

En tercer lugar, "la percepción y valoración de las personas que visitan el parque" se ha analizado con las reseñas de opiniones compartidas en Google Maps, un total de 12.513 en el momento de la consulta (27/10/2019). Estas opiniones han sido de gran interés, pues expresan lo que las personas han visto, observado y hecho como 
usuarias, convirtiéndose en una fuente alternativa a las encuestas o entrevistas y acorde con los planteamientos de la Teoría Fundamentada, al tratarse de opiniones inmediatas, espontáneas y no dirigidas, pues destacan aquello que más ha llamado la atención. El análisis de su contenido se ha realizado con un programa CADQAS (Atlas.ti), quedando patente el potencial de esta información para reflexionar sobre la identidad del lugar del parque como espacio público. Sobre este recurso cualitativo es importante mencionar que no está muy definido si forma parte de la etnografía digital (González \& Hernández, 2008), ya que las personas que opinan no lo hacen interactuando con las que lo han hecho previamente, aspecto que caracteriza en esencia a las redes sociales donde se generan foros de opinión. Por otro lado, las opiniones son dejadas por individuos de los que se desconoce cualquier información, salvo un nombre y el tiempo transcurrido desde que se hizo la valoración en el momento de la descarga (Figura 1). Esto último explica que algunas citas textuales que aparecen en el artículo solo estén datadas con el número de la reseña, de acuerdo con su orden en el momento de la consulta.

FIGURA I | Reseñas del parque Juárez

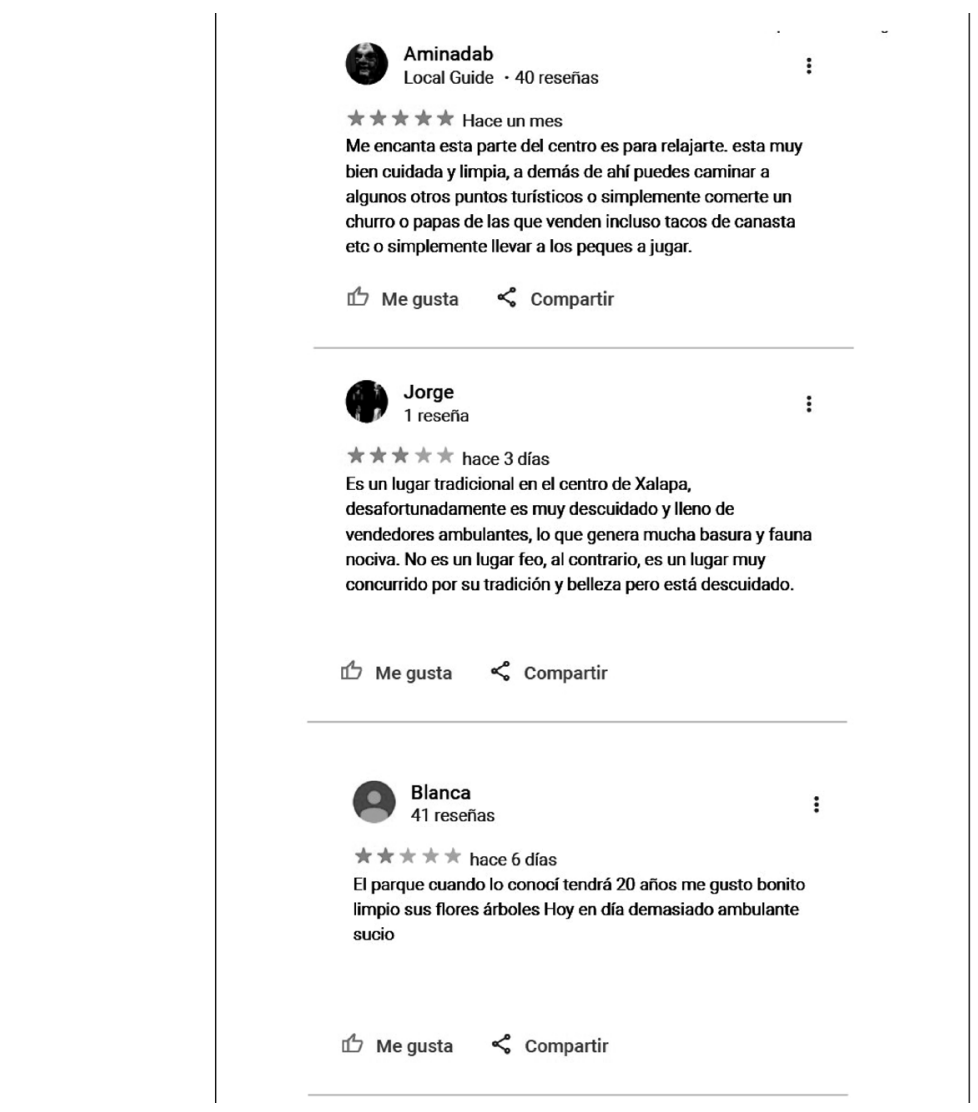

FUENTE: GOOGLE MAPS (CONSULTA 23/03/2020) 
En cuanto al trabajo de campo, se desarrolló en varios momentos: marzo de 2016, julio de 2018 y octubre de 2019, en diferentes franjas horarias, de 9:00 a 21:00 horas y todos los días de la semana, cubriendo un total de, aproximadamente, 270 horas de observación. Durante este tiempo se realizaron croquis para el levantamiento del plano del parque (Figura 7) y se procedió a la observación directa de las escenas públicas urbanas (Gomes, 2008; Gomes \& Berdoulay, 2010), según microlugares. Las observaciones fueron anotadas en el cuaderno de campo y las escenas captadas en registros fotográficos, material que fue analizado posteriormente con el mismo procedimiento aplicado a las opiniones. A las jornadas de campo se suman otras visitas como "participante", ya que el parque es un lugar de frecuente uso para llevar a los nińos, pasear con algún familiar o atravesarlo para ir de un lugar a otro. La experiencia vivida en estas visitas ha sumado en el momento de realizar el análisis.

\section{El devenir histórico del parque Juárez}

Xalapa-Enríquez, capital del Estado de Veracruz, es la ciudad donde se localiza el parque Juárez; con 488.531 habitantes en 2020 y situada a unos $350 \mathrm{~km}$ al este de Ciudad de México, se asienta sobre las estribaciones orientales del Cofre de Perote. Se trata de una ciudad de servicios, con intensa actividad comercial y una agitada vida universitaria, lo que la convierte en un polo de atracción importante y en el centro de una incipiente área metropolitana conformada por 8 municipios más y casi 800.000 habitantes. Urbanísticamente creció de forma considerable entre 1950 y 1980, cuando la trama urbana empezaba a desbordar el centro histórico y a expandirse sobre todo en dirección norte. Su centro, declarado Zona de Monumentos Históricos y Artísticos, da cobijo al parque Juárez, uno de sus principales pulmones verdes, importante área de esparcimiento y nodo de referencia en el conjunto urbano. El parque se asienta sobre una terraza natural con un considerable desnivel en su parte sur, lo cual favorece atractivas vistas sobre la ciudad y hasta el Cofre de Perote y el Pico de Orizaba. Su centralidad resalta por esta ubicación y por ser el centro de la zona más dinámica de la ciudad, donde se haya envuelto por edificios de usos diferentes que lo definen como un centro cívico (Figura 2), un "lugar de lugares” al que se llega y del que se parte en dirección a otros destinos.

Como en muchas ciudades de América Latina, el parque Juárez es un espacio público que previamente tuvo un uso religioso: el convento franciscano de la Natividad de Nuestra Señora, construido a partir de 1536 y cuya localización se justifica por su proximidad a los cuatro barrios que la orden religiosa pretendía unificar en lo que posteriormente sería la ciudad de Xalapa. Se trata, pues, de una localización estratégica que el paso del tiempo ha convertido en un lugar central. La desaparición del edificio religioso en el siglo xIx está relacionada con la desamortización y la expulsión de los monjes que lo habitaban. Se inició entonces un proceso de deterioro acelerado, al ser ocupado por las tropas norteamericanas en la guerra entre México y Estados Unidos (1846-1848). Su posterior abandono propició la ocupación del solar por el actual parque, levantado en 1892 en honor al Benemérito de las Américas Benito Juárez. 
FIGURA 2 | Localización del parque Juárez en el centro de Xalapa

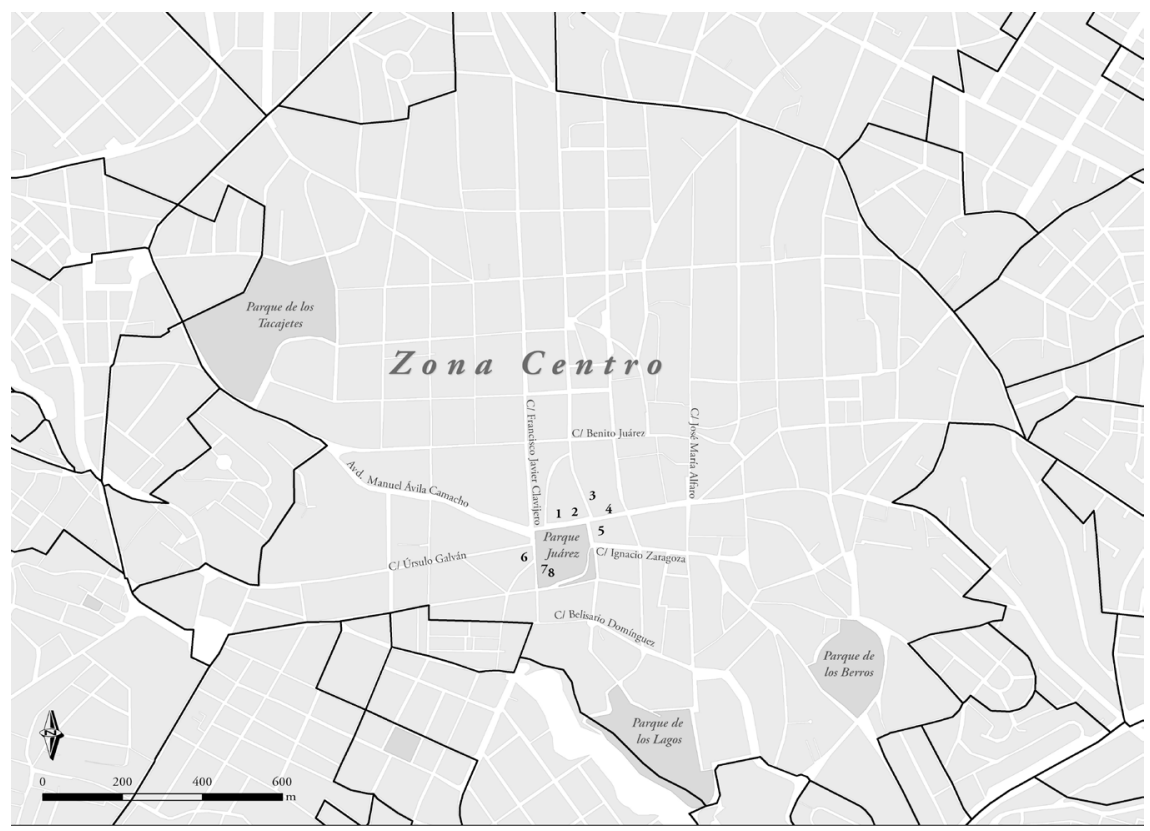

1. Palacio Municipal; 2. Cafe tería La Parroquia; 3. Catedral; 4. Plaza Lerdo; 5. Palacio de Gobie mo; 6. Biblioteca Carlos Fuentes; 7. Museo Casa Xalapa; 8. Pinacoteca Diego Rivera.

FUENTE: ELABORACIÓN PROPIA

Su diseño, incluso su construcción, se contextualiza en la nueva concepción urbanística que recorría Europa y América entre la segunda mitad del siglo xix y comienzos del xx, que en Xalapa -como en otras ciudades- se refleja en la iluminación a gas de las vías públicas, la introducción del tranvía, el abastecimiento de agua, la pavimentación de calles y obras de drenaje, la recogida de basura, la señalización, etcétera (Segarra, 2016). Estas mejoras urbanas eran también el reflejo de una mayor estabilidad política y riqueza, siendo la instancia política y las clases altas las que "se ocuparán de dar a las ciudades una apariencia nueva, acorde con su importancia y (...) pretensiones de lujo inspiradas en el ya obsesionante ejemplo de París" (Romero, 1999 , p. 264), condiciones visibles en la construcción y diseńo de grandes parques urbanos inspirados en los londinenses y parisinos, o en el mismo Central Park de Nueva York, con los que se pretendía, además, poner orden en el espacio público.

Aunque los espacios relacionados con la naturaleza tienen una larga tradición que en América Latina se remonta al siglo xvi, la novedad de los construidos en el siglo XIX es su función de higienización, "con una naturaleza escenográfica dispuesta como espectáculo para contemplar y diseñados deliberadamente como paisajes (...) concebidos como algo hermoso (...) íntimamente ligados a la noción de embellecimiento" (Arango, 2012, p. 91). En este contexto, las plazas, jardines y parques se convirtieron en el escaparate de las clases altas y de poder. En ellos se copió 
el denominado 'estilo francés', como reflejo de modernidad de influencia europea (Sánchez, 2013). Se hizo así "frecuente encontrar las mismas luminarias, fuentes o bancos (...) en Roma, Buenos Aires, México o Shanghái” (Segarra, 2016, p. 227) y "la recurrencia de los mismos elementos paisajísticos: arborización, senderos, plazoletas, jardineras, parterres, fuentes y espejos de agua (...), produciendo un espacio público (...) abierto a todo el mundo, confortable y agradable a la vista, no destinado al juego y otras actividades similares - puesto que está prohibido pisar el césped de los jardines y parterres-, estando pensado para la contemplación pasiva” (Gamboa, 2003, p. 15). En general, se trata de espacios públicos de convivencia para estar y reposar: "cada quien puede llegar y quedarse quieto, contemplando, y salir cuando se aburra (...) un espacio urbano amplio (...) usado en un tiempo que interrumpe las actividades citadinas ordinarias (...) con una delimitación espacial interna distinguible que especializa las áreas" (Vergara, 2006, pp. 152-153).

Todos estos aspectos, y otros, se observan en el parque Juárez, concebido como tal desde su origen, un ejemplo del "jardín europeo traído a la América Latina durante el siglo xIx” (Rangel, 2001, p. 321). En general, los espacios públicos de ocio formaban parte de un amplio proyecto de embellecimiento e higienización. A ello se suma la función de recreación y entretenimiento, junto con la de visibilizar valores culturales, patrios e institucionales propios de cada país (Salazar, 2017; Salazar, 2007), lo cual explica la colocación de bustos o esculturas de personalidades importantes del ámbito político y civil (Figura 7). Tenían, además, un propósito de regulación normativa del uso y comportamiento de la ciudadanía (Gamboa, 2003; Sevilla-Buitrago, 2014; Trevińo, 2013), en un momento en que el crecimiento de las ciudades absorbía la llegada de inmigrantes del ámbito rural, con hábitos propios de este medio.

Sin duda, el parque Juárez es un buen ejemplo de la construcción de un parque en una ciudad mexicana a finales del siglo xIx; y aunque en la actualidad mantiene los mismos elementos que lo definieron en su origen, ha sufrido desde entonces algunas transformaciones. Las más evidentes tuvieron lugar en la década de 1970, y la más importante está relacionada con la reorganización del tráfico, al estar localizado el parque en el cruce de importantes calles (Figura 2). El nuevo plan de movilidad implicó atravesarlo con una vía soterrada que conecta las calles Ávila Camacho e Ignacio Zaragoza, y remodelar las escalinatas de tipo imperial, que permitían su acceso en el lado oeste, uno de los de mayor desnivel, y en cuya parte central se albergan -hasta este momento- instalaciones de ocio (biblioteca, acuario, teatro). Este acceso ya había sido modificado anteriormente (Figura 3, Figura 4 y Figura 5). El soterramiento no solo transformó el acceso, también el hotel Juárez, que fue demolido e incorporado como parte de la actual terraza-mirador (Figura 7). Este hotel, en ocasiones identificado como Teatro Victoria, asumía funciones de ocio diversas: salón de baile, billares, cine, pista de patinaje, lo que demuestra la capacidad del parque para concentrar actividades de ocio diversas a lo largo del tiempo. Otro cambio de este momento fue la sustitución del Estanque de los Patos por un teatro al aire libre (Figura 6). 
Figura 3 (izquierda), Figura 4 (centro) y Figura 5 (derecha)

| Diferentes soluciones al acceso al parque Juárez desde el oeste
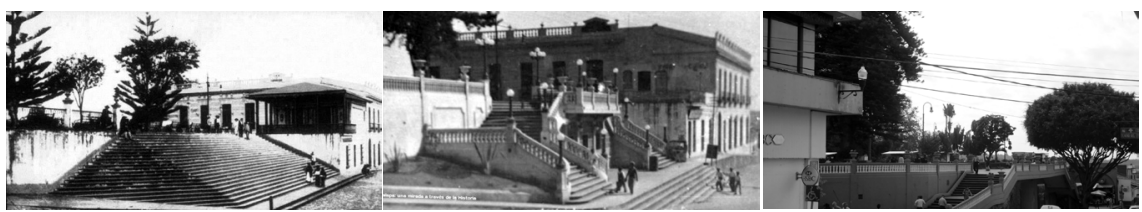

FUENTE: WWW.XALAPAVERACRUZ.MX/WP-CONTENT/UPLOADS/2OI7/05/PRIMERA_ ESCALINATA_DEL PARQUE_JUAREZ XALAPA.JPG Y HTTPS://GOO.GL/ maps/4KHNQVzNDtK\#XalapaunaMiradaATravésdelaHistoria\#XalapaenlaHistoria (CONSULTADO I7-IO-2OI8); Y ARCHIVO PERSONAL

Una tercera transformación fue la ampliación del equipamiento de permanencia, al sustituirse las rejas y/o bordes que delimitaban las zonas ajardinadas por borduras de obra, lo que supuso ampliar los asientos, actuando los parterres como espaldar (Figura 9). Pese a estos cambios, el parque ha mantenido en esencia el diseño original, algo importante en la construcción de la identidad del lugar y en la imagen de la ciudad como un legado heredado.

FIGURA 6 | El teatro que sustituye al Estanque de los Patos

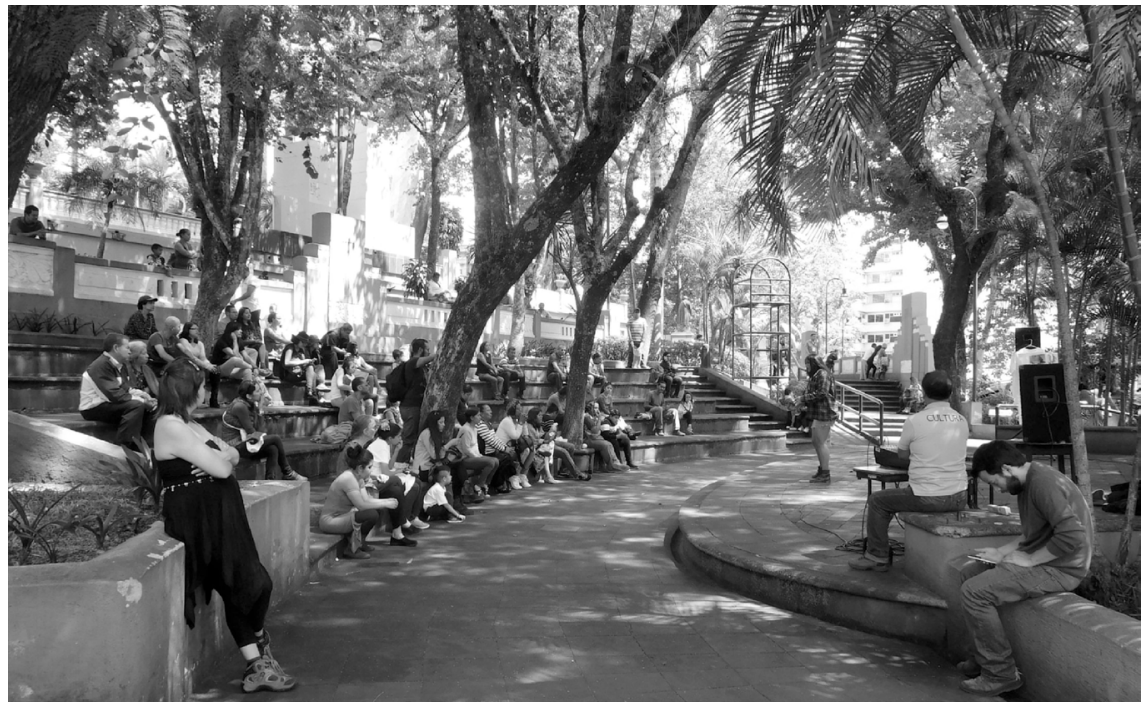

FUENTE: ARCHIVO PERSONAL

\section{La estructura espacial del parque y sus microlugares}

El parque se ubica en una fuerte pendiente de unos 25 metros de desnivel que le hace adoptar una estructura aterrazada perfectamente integrada en la trama urbana de empinadas calles, con vistas que constituyen en sí uno de sus atractivos. Esta orografía permite diferenciar en el parque tres niveles (Figura 7): el nivel I (norte), 
el de mayor extensión, donde se encuentra el Monumento al Benemérito y que es atravesado por la vía soterrada antes mencionada; el nivel iı (centro), que acoge el teatro al aire libre y el centro cultural, el ágora de la ciudad; y el nivel III, que consolida su forma cuadrangular en la esquina sureste y se reconoce por albergar el conjunto escultórico de las Virtudes.

FIGURA 7 | Plano de la estructura espacial y microlugares del parque Juárez

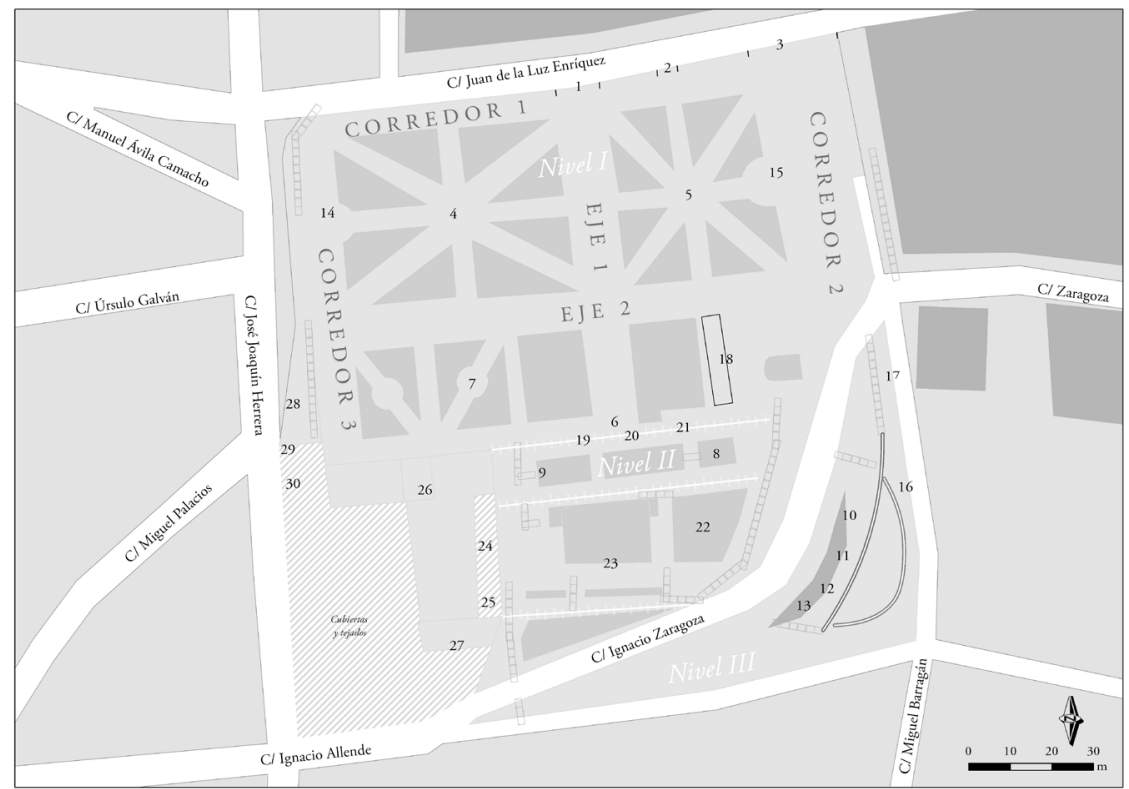

1, 2 y 3: Accesos; 4. Busto F.I. Madero; 5. Busto J. de la Luz Enríquez; 6. Escultura Benito Juárez; 7. Busto Ing. L.G. Rendón; 8. Escultura Ing. Agustín Ruíz; 9. Escultura de Clásica; 10. Virtud Templanza; 11. Virtud Prudencia; 12. Virtud Justicia; 13. Virtud Fortaleza; 14, 15, 16 y 17: Fuentes; 18. Pérgola de hierro; 19. Servicio de mantenimiento; 20. Baños públicos; 21. Espacio de internet gratuito; 22. Espacio infantil de la "Serpiente emplumada Quetzalcóalt"; 23. Anfiteatro; 24. Centro Cultural El Ágora; 25 y 26: Accesos a Cafetería Don Justo; 27: Telescopio y mirador; 28. Pinacoteca Diego Rivera; 29. Cafetería La Terraza; 30. Museo Casa Xalapa.

FUENTE: ELABORACIÓN PROPIA

Así, el diseño del parque ha sabido adaptarse a las características del relieve, concibiéndolo como un todo, al mantener las balaustradas, bancos de hierro, vegetación, borduras de obra, el encalado blanco y verde, y sobre todo su ambiente familiar y sentido de centralidad, no desplazado por otros espacios o por la relocalización de los usos de los edificios que lo envuelven. A esto se añade su estructura geométrica y ordenada, que integra diferentes microespacios que pudieran parecer aislados. 
El nivel I invita a pensar en una cruz latina, cuyo eje norte-sur parte de la entrada en la calle Juan de la Luz Enríquez hasta el Monumento al Benemérito. Es un pasillo amplio, con bancos a los lados, donde se celebran actividades cíclicas y/o cotidianas (Figura 8), incluida para ello la superficie cuadrangular del monumento. Este eje es cruzado por otro que discurre en sentido este-oeste. Su uso lo definen los puestos de botanas (venta de bebidas y alimentos) y boleros (limpiabotas). ${ }^{1}$ Ambas actividades se desempeñan en pequeñas estructuras de fácil montaje, pero de ubicación permanente entre banco y banco.

\section{FIgura 8 Preparación del tapiz del Día de Muertos}

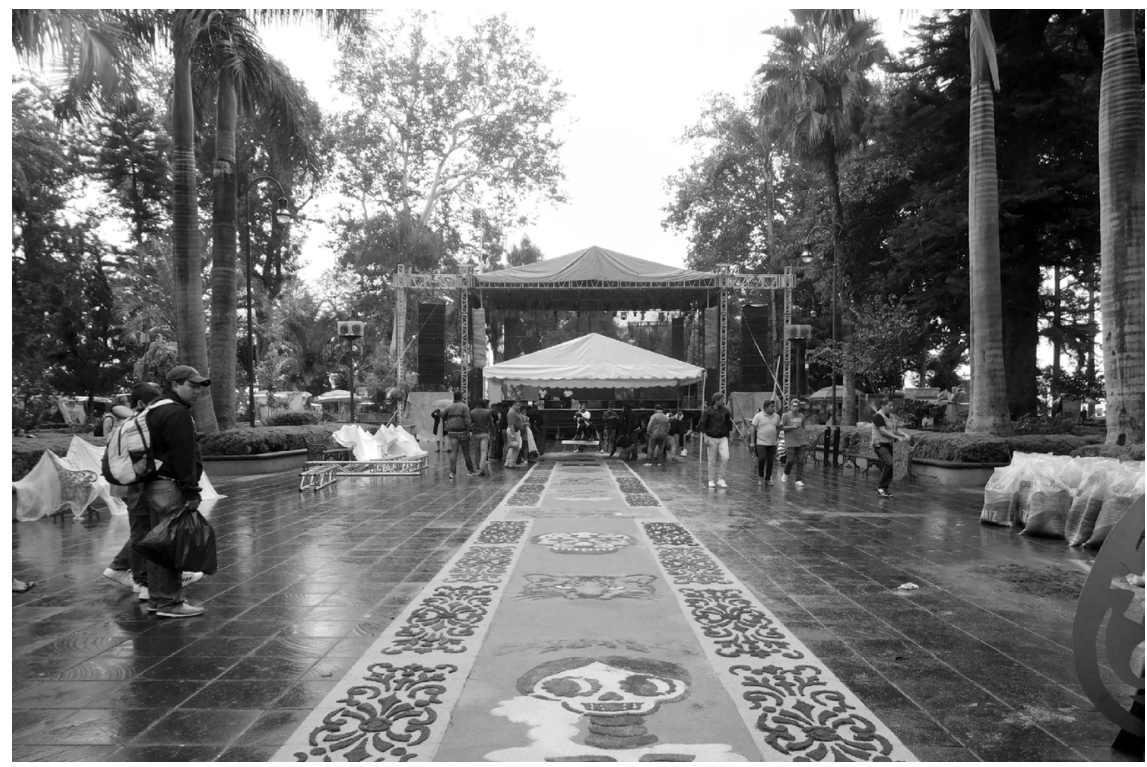

FUENTE: ARCHIVO PERSONAL

Este nivel I queda enmarcado por tres corredores, que lo limitan con otras tantas calles hacia las que miran los bancos de hierro. De dichos corredores, el que "cose" el parque al Palacio de Gobierno se configura por su amplitud y localización como un punto estratégico para actuaciones de artistas callejeros, venta ocasional, manifestaciones, y es de frecuente concurrencia.

Una tercera jerarquía de espacios son los sectores ajardinados que quedan entre los ejes y corredores. Al sur del eje oeste-este (Figura 7), se encuentran dos sectores simétricos y geométricos con un punto escultórico focal del que parten ocho parterres triangulares con vegetación de primor y árboles de gran porte, delimitados por arriates y borduras de obra, a los que dan entrada sendas fuentes de base circular y brocal bajo que hablan de la presencia del agua en Xalapa y del origen de la

1 Su presencia forma parte de la identidad del parque; aparecen ya en fotos de los ańos 1940, cuando esta actividad no tenía una ubicación fija. 
localización del convento. Su escala las asegura como otra posibilidad de permanencia (Figura 9), al tiempo que embellecen y aportan frescor.

FIGURA 9 | Sector ajardinado y componentes de permanencia

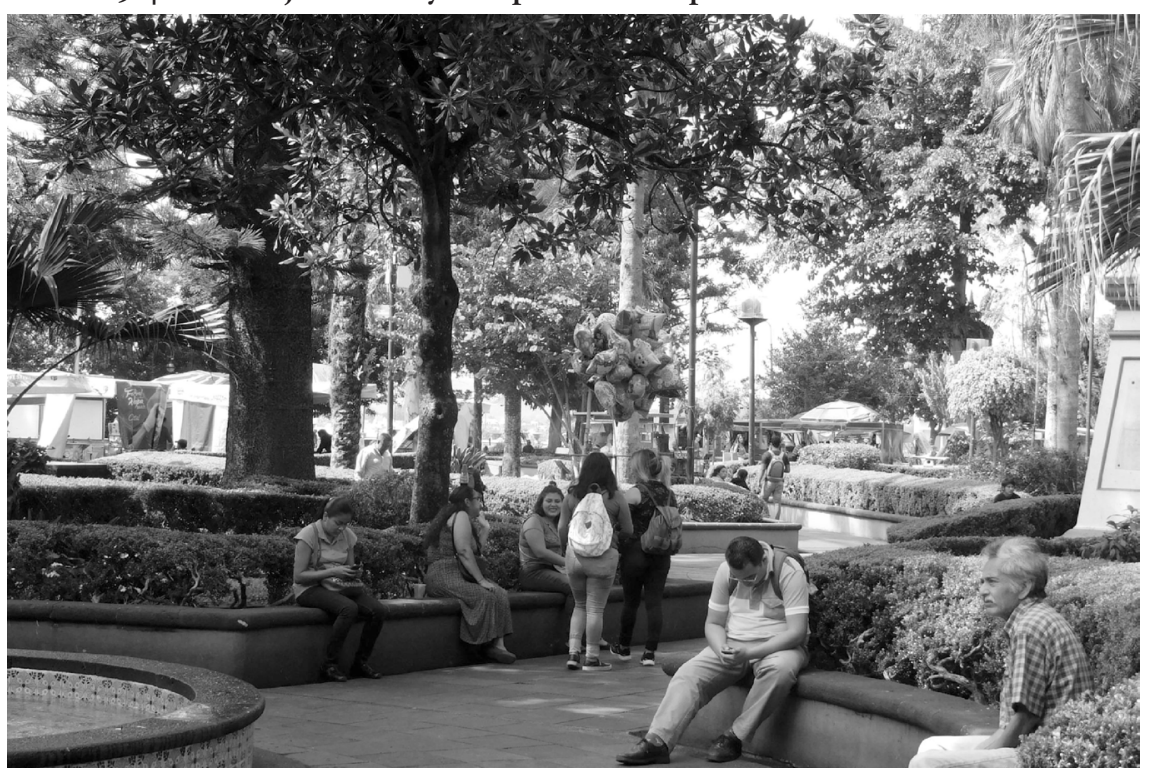

FUENTE: ARCHIVO PERSONAL

Al norte del eje oeste-este, la distribución de espacios no parece tan simétrica a primera vista. En ambos lados del Monumento al Benemérito se sitúa un parterre cerrado (Figura 7). En la parte posterior izquierda, una terraza rectangular aísla del bullicio y permite distraerse en la contemplación de lo que sucede en los niveles ir y III y más allá; y un poco más a la izquierda, un pequeño espacio con un banco queda cobijado tras un gran árbol. Entre ambos espacios, una pérgola cubre un improvisado restaurante siempre concurrido. A la derecha del monumento, el espacio parece adquirir de nuevo el "orden". Así, a continuación del parterre cerrado se encuentran dos sectores ajardinados simétricos, con un pasillo que los atraviesa en sentido transversal y en la misma dirección (Figura 7).

$\mathrm{Al}$ oeste de esta zona, dos grandes terrazas-mirador prolongan el parque hacia el sur hasta llegar al punto de mayor desnivel; es el lugar donde se situaba el hotel Juárez (Figura 3 y Figura 4), siendo ahora parte de la cubierta de los edificios que se encuentran en la parte inferior: pinacoteca Diego Rivera, cafetería Terraza del Parque, museo Casa de Xalapa, centro cultural Ágora de la Ciudad y cafetería Don Justo (Figura 7). Desde aquí se atisba un paisaje que llega más allá de los tejados y árboles de la parte sur del Xalapa más histórico: el Pico de Orizaba y el parque natural Cofre de Perote. Esta vista es uno de los mayores atractivos de la visita al parque y un fuerte elemento de su identidad. 
El nivel II es más pequeño, pero también más complejo por la diversificación de microlugares, las muchas escalinatas desdobladas en rampas y los diferentes equipamientos. La zona central está ocupada por el teatro (Figura 6): un espacio abierto que puede ser usado para actuaciones programadas o espontáneas. A su izquierda se encuentra la única zona infantil, ocupada por la serpiente emplumada Quetzalcoalt; a la derecha, la entrada al centro cultural El Ágora de la Ciudad (Figura 7); a continuación, una escalinata que conduce a la cafetería Don Justo; y otra, bastante empinada, que llega hasta la calle Ignacio Zaragoza. Al norte y sur de esta zona central, dos más de características similares son ocupadas por parterres. En la del norte se encuentran los baños públicos y una sala de internet.

Finalmente está el nivel III, protagonizado por el conjunto escultórico de las Virtudes (Figura 10). En la parte posterior del conjunto, el diseño se resuelve con pasillos que discurren siguiendo la pendiente de la calle y facilitando la circulación peatonal. Espacialmente, y a pesar de quedar algo aislada por el paseo del Ayuntamiento, ${ }^{2}$ el parque se consolida con esta "gran esquina" que le confiere una forma cuadrada al conjunto. Las esculturas de las Virtudes reinterpretan las de estilo clásico y adornan el paseo con los símbolos de los valores que promueven el entendimiento en una sociedad: Justicia, Fortaleza, Templanza y Prudencia.

\section{Figura io | Conjunto escultórico de las Virtudes}

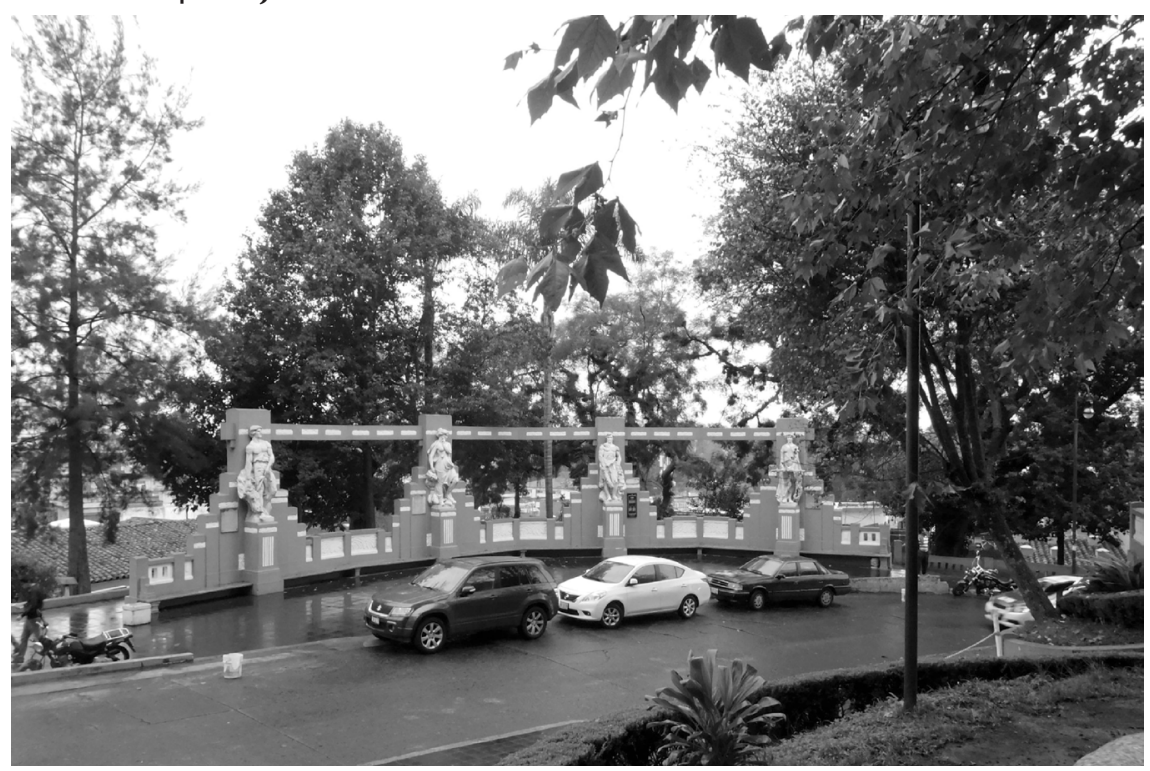

FUENTE: ARCHIVO PERSONAL 


\section{Elementos de la identidad del parque Juárez}

\section{Lugar central, popular y familiar}

Desde el punto de vista de la percepción de la población y de sus prácticas de apropiación, hay tres elementos identificadores del parque: su centralidad, su sentido popular y el ambiente familiar. La centralidad está resaltada por su localización y proximidad a lugares importantes del centro y para la ciudadanía (Figura 2): "es el parque central de la ciudad de Xalapa; ubicado al lado del Palacio de Gobierno y enfrente del Palacio Municipal, es un punto de encuentro de artistas urbanos, jóvenes y familias que gustan de pasar sus tardes en un ambiente familiar" (opinión 7.532/12.513, consulta 27/10/2019). Es el lugar al que se llega desde otros lugares, desde el cual se parte hacia otros destinos o que se atraviesa en un agradable paseo, como un "pasillo" con múltiples alternativas; es, en definitiva, un espacio de confluencias (Del Valle, 2004). Por otro lado, la proximidad a edificios administrativos hace que el parque sea su "sala de espera"; es aquí donde muchas personas esperan a resolver trámites administrativos; o es el mismo personal de estos organismos el que lo utiliza para tomar su almuerzo o un descanso.

La centralidad lo ha convertido en un lugar histórico, tradicional, típico, emblemático, manteniendo como legado su diseńo y ambiente popular, término que debe ser entendido aquí como indicador de cohesión social y democratización. El perfil de usuarias y usuarios cambia según la franja horaria y el día de la semana: personas mayores solas o acompańadas, por las mańanas; hombres y mujeres jóvenes que quedan, avanzada la tarde, para encontrarse; adolescentes con uniformes que transitan pausadamente después de la jornada escolar; personas que resuelven su desayuno o almuerzo en alguno de los puestos de botana, y/o mejoran el lustre de sus zapatos; las que acuden a contemplar las vistas al caer la tarde; quienes usan los lugares más espaciosos y tranquilos para algún ensayo; padres y madres que atienden a niños y niñas que corretean en diferentes direcciones, sobre todo los fines de semana; personas que esperan sin afán con papeles en la mano. Nadie molesta a nadie, las personas saben donde tienen que estar y lo que deben hacer. Esto, observado a lo largo del tiempo, convierte al parque en un excelente termómetro de interacción e integración social (Rizzo, 2010b).

Indudablemente, percibir el parque como un lugar popular y de ambiente familiar explica que se le humanice con "bondades", como ser amable, amigable, agradable, acogedor, confortable. Es asignarle atributos vinculados con la experiencia de los sentidos (Fu-Tuan, 1974); es estar en un espacio pensado a escala para las personas (Gehl, 2015), seguramente el mayor éxito de un espacio público. Otro aspecto que lo hace un lugar atractivo para ir, estar y quedarse es su estado de conservación, limpieza y seguridad, que se apoya en la concurrencia de personas y el ambiente familiar. La seguridad está relacionada, a su vez, con las actividades desempeñadas por los boleros, los puestos de botana, la cafetería y la instalación de uno de los centros culturales más importantes de la ciudad, el Ágora; también con ser un lugar de paso y con la presencia de personal de seguridad y cámaras de videovigilancia. 
La vegetación, el mobiliario y las actividades: componentes para la permanencia Cabe preguntarse qué ofrece el parque para ser un lugar popular, concurrido y confortable. La repuesta está en tres elementos de permanencia: la vegetación, el mobiliario y la oferta de actividades. Uno de los retos de un espacio público es que su diseño haga que las personas quieran visitarlo y permanecer en él. Esto asegura su nivel de éxito, ya que no basta con crearlo: hay que equiparlo para propiciar el encuentro, la sociabilidad y cumplir los estándares de calidad de vida urbana (Páramo, 2010), siendo el tiempo de permanencia uno de los indicadores de esa calidad (Núñez \& Higueras, 2018).

En el parque Juárez, la exuberante vegetación de árboles de gran porte forma parte de su imagen y mobiliario desde el momento de su creación y es una de las ofertas que más motiva la visita; los árboles proporcionan sombras en las horas de más calor y permiten resguardarse de las primeras gotas de lluvia; generan una sensación agradable y placentera incluso cuando se va de paso, constituyendo un remanso de paz en el ajetreado centro. Además, la vegetación de parterres actúa como pantallas que pueden aislar del ruido los días más concurridos.

Del mobiliario destaca el que facilita estar sentado, ya que así transcurre buena parte de la estancia y así se realizan muchas de las actividades por las que se concurre; los bancos son microespacios de la vida en lo público, una forma de apropiación que nos vincula al lugar; nos pertenecen durante el tiempo que nos acogen. Están para charlar, para leer, para descansar; son lugares desde donde observar y cuidar, donde tomar algo de alimento, donde darle el pecho al bebé o cambiar sus pañales, donde pensar, donde imaginar, donde contemplar lo que pasa. Todas estas actividades, y más, se hacen en los bancos de hierro que por doquier están en el parque Juárez; son los que siempre han estado, con un diseño que reúne las características de confort, durabilidad y fácil mantenimiento. A este sencillo, básico e importante mobiliario se suman las borduras de obra que delimitan todas las zonas ajardinadas (Figura 6). Otros lugares facilitan también el asiento, como las gradas del teatro, la plataforma del Monumento del Benemérito, el brocal de las fuentes, o la misma balaustrada, que permite apoyarse cómodamente para esperar, descansar o mirar.

El tercer elemento de permanencia es la diversidad de actividades, ya que "debe haber condiciones favorables para deambular y entretenerse en esos espacios, así como para participar en un amplio abanico de actividades sociales y recreativas (...). El diseño de cada uno de los espacios y de los detalles, hasta el más pequeño componente, son factores determinantes" (Gehl, 2009, p. 143). Aquí, el entretenimiento está asegurado; y no porque exista una gran diversidad de equipamientos, sino porque las personas utilizan el espacio más allá de la intención de su diseño (Arango, 2012; Gamboa, 2003). Las actividades son variadas y cambiantes de un día para otro o incluso por franjas horarias: una actividad infantil, una sesión de cuentacuentos, una exposición de fotografías, un payaso que congrega en torno a él a grandes y pequeños, una muestra de café, la preparación de la fiesta del Día de Muertos, un concierto, artistas, grupos de música y danza, asociaciones que visibilizan una causa social, un acto religioso, promociones comerciales... Todas entretienen y son posibles por la forma en que se articulan los microlugares y la 
misma permisividad socioespacial; y algo importante: todas son gratuitas, importante para familias que van a pasar el día.

Es interesante señalar que las actividades que se realizan al aire libre son las más celebradas por la población como parte de la identidad del parque, a pesar de encontrarse aquí el Ágora, la Casa Museo de Xalapa y la pinacoteca Diego Rivera. En realidad, solo dos espacios se reconocen como elementos identitarios: el mirador y el espacio infantil Quetzalcóatl, siendo el primero uno de los lugares a los que acuden más personas para disfrutar de las vistas, las cuales quedarían incluidas dentro del parque como parte de sus dotaciones.

Finalmente, el parque cuenta con dos actividades económicas que le suman identidad: la tradicional presencia de boleros y los puestos de botana. Sin la oferta variada de comida y bebida (jugos, refrescos, helados, papas fritas, elotes, esquites, plátanos fritos, chicharrones, cacalas, tortitas de epazote, malanga, banderillas, hamburguesas, hotdogs y churros), no se entendería el parque. Esta oferta se amplía con el improvisado pero diario restaurante bajo la pérgola y la selecta cafetería Don Justo, situada en la terraza-mirador (Figura 7), que se completa con la cafetería La Parroquia al otro lado de la calle Enríquez, desde la cual la vista del parque constituye un entretenimiento, mientras la misma cafetería forma parte de su imagen. Algo más discreto, pero también concurrido es el café La Terraza del Parque, junto a la entrada de la pinacoteca Diego Rivera.

\section{El uso del parque Juárez: para qué, cuándo y con quién}

Quienes acuden al parque lo visitan para hacer algo. La diversidad de actividades toma en consideración la clasificación de Velásquez y Meléndez (2003), según la cual se identifican actividades pasivas, que no requieren ejercitación física (reflexionar, relajarse, descansar, observar, o no hacer nada); y actividades activas, que requieren un esfuerzo físico (pasear, comer, patinar). Algunas son de difícil clasificación y en cada caso se ha procurado atender las que se hacen en compañía y las que se realizan de forma individual. Entre las actividades compartidas están las de interacción social: estar con otras personas (familia, amigos, la pareja) "para disfrutar con ellos y del momento" (opinión 3.020/12.513, consulta 27/10/2019), que constituyen la mejor expresión de la función sociabilizadora que tienen los espacios públicos, incluida la del encuentro fortuito para aquellas personas que ven en la visita la oportunidad de conocer a alguien (Filipe \& Ramírez, 2016; Gomes \& Ribeiro, 2018; Ramírez, 2007; Trevińo, 2013). La actividad más frecuente es la de pasear, que puede realizarse a cualquier hora y siempre con alguna intención: tomar un helado y comer algo rápido, disfrutar de la vegetación, ver el atardecer desde el mirador, relajarse, etcétera. Aunque se realicen en compañía, la mayor parte de las actividades pueden realizarse individualmente y están pensadas para disfrutar.

Si bien cualquier momento puede ser adecuado para la visita, este varía según el motivo. Así, "ir a dominguear al parque" es una de las alternativas que, desde antiguo, se ofrece a la ciudad para el ocio. Fotografías de comienzos del siglo xx reflejan un ambiente que, en esencia, apenas difiere del actual; el domingo es el momento en que "se llena de gente que pasea con amigos, familiares, turistas, los que buscan pareja” (opinión 1.652/12.513, consulta 27/10/2019). Es cuando hay más 
actuaciones de artistas callejeros y el entretenimiento está asegurado. Este ambiente se puede encontrar desde el mismo viernes por la tarde. Un ambiente tan colorido y animado no se podría explicar por la falta de espacios públicos en la ciudad; de hecho, si se toma como punto de referencia el parque Juárez, hay varias alternativas cercanas: el parque de los Tacajetes (a 14' andando), el parque de los Berros (a 11'), la zona de Los Lagos (a 17’), pero en el parque Juárez confluyen muchos elementos de un espacio público de ocio: ubicación en el centro, vegetación, entretenimiento, vistas, mobiliario para permanecer, microlugares para encontrar tranquilidad en medio del bullicio, actividades diversas, instalaciones culturales. Después del fin de semana, el parque empieza a recuperar la serenidad y se prepara para recibir el lunes con un ambiente más sosegado, pudiéndose observar en días fijos actividades concretas, como el izamiento de la bandera; o aprovechar las horas tempranas para ver el paisaje desde el mirador, una de las actividades que nadie se pierde, sobre todo si se visita la ciudad como turista, o se está de paso.

\section{Conclusiones}

En el sitio que dejó el convento franciscano, la historia ha ido consolidando un espacio que nunca ha perdido su impronta, que más bien ha ido fortaleciendo su identidad y sentido del lugar. Desde sus orígenes, el parque Juárez se ha confirmado como un espacio público con un claro carácter democrático: la concurrencia de personas de diferente perfil sociodemográfico que conviven y socializan en un mismo lugar, donde se comparte el mismo "hacer" (pasear, descansar, charlar, enamorar, ver la vida pasar, encontrar un rayo de sol que caliente o una sombra que alivie las horas del día de más calor).

El parque es como un gran "laberinto ordenado" donde todas las partes están conectadas y son accesibles. Es un espacio a escala humana: los bancos, las borduras de obra y las balaustradas invitan a entrar, estar y permanecer. Lo más exuberante, y a veces inalcanzable con la vista, es la vegetación que cobija y da frescor, creando un ambiente saludable, amable y reconfortante. La diferenciación de espacios no supone una jerarquización espacial ni de usos. Apenas se puede decir que los espacios estén especializados para determinadas actividades, aun cuando se pensase así en su diseño. No hay unos elementos que dominen sobre otros ni desde el punto de vista físico ni desde el memorial, salvo la presencia del Monumento al Benemérito; y hasta en este caso, la escultura no termina de estar centrada en el eje principal, haciéndose a un lado para dejar más espacio a las posibles actividades; los restantes personajes históricos observan silenciosos la vida del parque, hasta pasar casi desapercibidos.

El parque es la expresión de la dinámica del centro, siendo su ritmo parecido al de este, pero imaginado como una isla de tranquilidad y entretenimiento; no solo está en el centro desde el punto de vista geográfico, es el centro. En él se observan muchos de los aspectos que se han tomado como referencia para el análisis: en primer lugar, el diseño y la intención de los parques como espacios públicos pensados para el deleite, la observación, el contacto con la naturaleza (Gamboa, 2003); como espacios públicos de convivencia y sociabilidad (Gomes \& Ribeiro, 
2018); como espacios interactivos, democráticos, significativos, incluyentes y tolerantes (Ramírez, 2007); como buenos indicadores de la calidad de vida urbana, por la oferta de su infraestructura y mobiliario urbano y la satisfacción en cuanto a la posibilidad de permanencia, seguridad, comodidad, confortabilidad (Páramo, 2010); y como depositario de la memoria colectiva (Salazar, 2017), que hace al parque un lugar sentido (Lindón et al., 2006) y (con)sentido.

Como se ha mencionado anteriormente, el parque Juárez reúne todas las características para visitarlo solo o en compañía; es también el lugar donde encontrarse, donde quedar, o donde el encuentro puede ser inesperado; domina el efecto sorpresa que se le pide a los espacios públicos para que resulten más atractivos: es ir y saber que algo que no te esperas sucederá por encima de lo cotidiano del lugar. Y es, sobre todo, un lugar familiar, lo que le imprime el carácter tradicional de un lugar típico mantenido a lo largo de la historia.

Finalmente, el parque reúne muchas de las características que, según Gehl (2015), definen un buen espacio público: la proximidad ejemplificada con la localización, la confianza con la concurrencia de personas, los usos de los edificios que lo envuelven, la sobreposición de actividades diurnas y nocturnas, la iluminación, la vigilancia, el mantenimiento, etcétera; la protección del clima con grandes y exuberantes árboles; el equipamiento para permanecer sentado, de pie o apoyado, y hacer paseos; y la posibilidad de la interacción social mediante la disposición de los bancos y borduras de obra, la facilidad para ver, escuchar y conversar y para la creatividad. Estas características son también un claro ejemplo de la interpretación de los espacios públicos, en este caso un parque, como espacios de sociabilidad que favorecen las relaciones sociales y fortalecen el tejido social y, por ende, aportan identidad a la ciudad a través de uno de los elementos de su trama urbana, convirtiendo la experiencia espacial en identidad colectiva.

\section{Agradecimientos}

Este artículo forma parte de la investigación realizada por la Dra. Carmen Egea Jiménez, desde el 1 de mayo al 31 de agosto de 2012 en el Centro de Investigaciones Tropicales de la Universidad Veracruzana (Xalapa, México), tiempo durante el cual realizó un inventario de espacios públicos en el Centro de la Ciudad, ampliando posteriormente la información del espacio analizado aquí. La estancia en dicho centro estuvo subvencionada por el Ministerio de Ciencia e Innovación (España), en el marco del Programa Salvador de Madariaga (Referencia PR2O I I-0470). 


\section{Referencias bibliográficas}

Arango, S. (2012). Ciudad y arquitectura. Seis generaciones que construyeron la América Latina moderna. Fondo de Cultura Económica.

Arendt, H. (1958). The human condition. University of Chicago Press. Trad. español: La condición humana, Círculo de Lectores, 1999.

Ayala, E. T. (2015). La apropiación y modos de ocupación del espacio público. El caso de la avenida 6a de la ciudad de Cúcuta. DEARQ-Revista de Arquitectura, (17), 74-85. https://www.redalyc.org/articulo.oa?id=341645612006

Berroeta, H. \& Vidal, T. (2012). La noción de espacio público y la configuración de la ciudad: fundamentos para los relatos de pérdida, civilidad y disputa. Polis, 31, 1-20. http:// journals.openedition.org/polis/3612

Borja, J. (2003). La ciudad conquistada. Alianza Editorial.

Borja, J. \& Muxí, Z. (2001). El espacio público, ciudad y ciudadanía. Diputación de Barcelona.

Cárdenas, S. (2017). Medir el uso del espacio público urbano seguro. Sociedad y Economía, (33), 33-54. https://doi.org/10.25100/sye.v0i33.5620

Del Valle, T. (2004). Identidad y cambio urbano en Tolosa (Gipuzkoa). Una reflexión desde la antropología social. Kobie, 11(5), 5-30. https://dialnet.unirioja.es/ejemplar/136340

Delgadillo, V. (2011). Patrimonio histórico y tugurios. Universidad Autónoma de la Ciudad de México.

Delgado, M. (1999). El animal público: hacia una antropología de los espacios urbanos. Anagrama.

Delgado, M. (2007). Sociedades movedizas. Pasos hacia una antropología de las calles. Anagrama.

Filipe, C. A. \& Ramírez, B. R. (2016). Discursos, política y poder: el espacio público en cuestión. Territorios, (35), 37-57. https://doi.org/10.12804/territ35.2016.02

Flores, P., Crawford, L., Palacio, M. P. \& Cruz, H. (2004). Imágenes ambientales y expresiones de euforia y disforia en el espacio público. El caso de las universidades en el perímetro urbano de Barranquilla (Colombia). Investigación \& Desarrollo, 12(1), 164-183.

Fu-Tuan, Y. (1974). Topophilia: a study of environmental perception, attitudes, and values. Prentice-Hall.

Fu-Tuan, Y. (1977). Space and place: the perspective of experience. University of Minnesota Press.

Gamboa, P. (2003). El sentido del espacio público. Revista Bitácora Urbano Territorial, 7(1), 13-18. https://revistas.unal.edu.co/index.php/bitacora/article/view/18775

García, Ó. M. \& Coral, L. A. (2004). Espacio público: el reto de la gestión. Revista Bitácora Urbano Territorial, 8(1), 103-109. https://revistas.unal.edu.co/index.php/bitacora/ article/view/18762

García, R. (2018). Identidades de los paisajes urbanos. Usos y puestas en valor. En B. Calderón (Ed.), Valores e identidad de los paisajes culturales. Instrumentos para el conocimiento y difusión de una nueva categoría patrimonial (pp. 177-200). Editorial de la Universidad de Granada.

Gehl, J. (1971 [2009]). La humanización del espacio público. La vida social entre los edificios. Reverte.

Gehl, J. (2010 [2015]). Cidades para pessoas. Perspectiva. 
Gomes, P. C. da Costa. (2008). Cenários para a geografia: sobre a espacialidade das imagens e suas significaçóes. En Z. Rosendahl \& R. L. Corrêa (Orgs.), Espaço e cultura: pluralidade temática (pp. 187-210). Editora da Universidade do Estado do Rio de Janeiro (EDUERJ).

Gomes, P. C. da Costa \& Berdoulay, V. (2010). Image et espace public: la composition d'une scène. Géographie et Cultures, 73, 3-6. http://gc.revues.org/1812

Gomes, P. C. da Costa \& Ribeiro, L. P. (2018). Sociabilidad pública en los parques urbanos de Río de Janeiro (Brasil). En C. Egea \& S. Coupleux (Coords.), Ciudad, vivir, habitar (pp. 169-182). Editorial de la Universidad de Granada.

González, M. \& Hernández, M. J. (2008). Interpretación de la virtualidad. El conocimiento mediado por espacios de interacción social. Apertura, 8(9), 8-20. http://www. udgvirtual.udg.mx/apertura/index.php/apertura/article/view/1180

Harvey, D. (2013). Ciudades rebeldes. Del derecho de la ciudad a la revolución urbana. Akal.

Habermas, J. (1962). The structural transformation of the public sphere: an inquiry into a category of a bourgeois society. MIT Press.

Hernández, M. (2005). Mejoramiento del espacio público en las colonias populares de México. Caso de estudio de Xalapa-Veracruz. Revista INVI, 20(53), 181-199. http://revistainvi. uchile.cl/index.php/INVI/article/view/339/982

Jacobs, J. (1967). Vida y muerte de las grandes ciudades americanas. Península.

Lefebvre, H. (1975 [1967]). El derecho a la ciudad (3a ed). Península.

Lindón, A., Hiernaux, D. \& Aguilar, M. Á. (2006). De la espacialidad, el lugar y los imaginarios urbanos: a modo de introducción. En A. Lindón, D. Hiernaux \& M. Á. Aguilar (Coords.), Lugares e imaginarios en la metrópolis (pp. 9-25). Anthropos.

López, J. C. (2012). El derecho al espacio público. Provincia, (27), 105-136. http://www. redalyc.org/articulo.oa?id $=55526545002$

Low, S. M. (2009). Cerrando y reabriendo el espacio público en la ciudad latinoamericana. Cuadernos de Antropología Social, 30, 17-38. https://doi.org/10.34096/cas.i30.2774

Muñoz, M. T. (2007). Ciudadanía y espacio público: Una recuperación del republicanismo arendtiano. EPISTEME, 27(2), 95-128. http://saber.ucv.ve/ojs/index.php/rev_ens/ article/view/13236

Núñez, A. \& Higueras, E. (2018). Altitud, variables climáticas y tiempo de permanencia de las personas en plazas de Ecuador. Urbe. Revista Brasileira de Gestão Urbana, 10(2), 414425. https://doi.org/10.1590/2175-3369.010.002.ao11

Ortiz i Guitart, A. (2006). Uso de los espacios públicos y construcción del sentido de pertenencia de sus habitantes en Barcelona. En A. Lindón, D. Hiernaux \& M. Á. Aguilar (Coords.), Lugares e imaginarios en la metrópolis (pp. 67-83). Anthropos.

Páramo, P. (2002). En busca de la identidad del bogotano: interacción con el pasado de la ciudad en el espacio público. Territorios, 8, 63-84. https://revistas.urosario.edu.co/ index.php/territorios/article/view/5684

Páramo, P. (2010). El espacio público y la calidad de vida urbana. En P. Páramo \& M. García (Coords.), Dimensión social del espacio público (pp. 15-26). Universidad Pedagógica Nacional, Colombia.

Petzold, A. H. (2017). ¿Público para quién? La performatividad de los límites en el espacio público. Universidad de las Américas Puebla (UDLAP). 
Ramírez, P. (2007). La ciudad, espacio de construcción de ciudadanía. Revista Enfoques, (7), 85107. http://www.politicaygobierno.cl/documentos/enfoques/7/96000704.pdf

Rangel, M. (2001). El carácter social del espacio público en Mérida. Visión físico espacial. FERMENTUM, Revista Venezolana de Sociología y Antropología, 11(31), 319-338. http:// www.saber.ula.ve/handle/123456789/20680

Rizzo, P. A. (2010a). El rol de los espacios públicos en los barrios suburbanos de la ciudad de Mendoza. Actas del IX Congreso Internacional de Geocritica. La planificación territorial y el urbanismo desde el diálogo y la participación. Buenos Aires, 2-7 de mayo de 2010, Universidad de Buenos Aires. http://www.filo.uba.ar/contenidos/investigacion/ institutos/geo_bkp/geocritica2010/620.htm

Rizzo, P. A. (2010b). El espacio público de la ciudad de Mendoza (Argentina). Espacio de disputa y expresión ciudadana. ACME: An International E-Journal for Critical Geographies, 9(2), 164-190. https://acme-journal.org/index.php/acme/article/view/865

Romero, J. L. (1999). Latinoamérica: las ciudades y las ideas. Universidad de Antioquia.

Salazar, C. (2017). La plaza fundacional en el siglo XX. La transformación en Lima, Bogotá y Santiago a través de los concursos arquitectónicos. Universidad Nacional de Colombia.

Salazar, Ó. I. (2007). Tiempo libre al aire libre. Prácticas sociales, espacio público y naturaleza en el Parque Nacional Enrique Olaya Herrera (1938-1948). Historia Crítica, (33), 186-208. http://www.scielo.org.co/pdf/rhc/n33/n33a08.pdf

Salcedo, R. (2002). El espacio público en el debate actual: Una reflexión crítica sobre el urbanismo post-moderno. Revista EURE - Revista de Estudios Urbano Regionales, 28(84), 5-19. http://dx.doi.org/10.4067/S0250-71612002008400001

Sánchez, G. G. (2013). Precursores del urbanismo en México. Trillas.

Segarra, S. (2016). Mobiliario urbano, imagen y ciudad. En S. Segarra, L. M. Valenzuela \& J. L. Rosúa (Coords.), Paisaje con+texto. Naturaleza | jardin | espacio público (pp. 223248). Editorial de la Universidad de Granada.

Sennett, R. (1977). The fall of public man. Alfred A. Knopf.

Sevilla-Buitrago, Á. (2014). Central Park y la producción del espacio público: el uso de la ciudad y la regulación del comportamiento urbano de la ciudad. Revista EURE Revista de Estudios Urbano Regionales, 40(121), 55-74. http://dx.doi.org/10.4067/ S0250-71612014000300003

Treviño, J. A. (2013). La dimensión pública del espacio urbano. Relevancia de plazas, paseos y parques vecinales para la generación, mantenimiento y reproducción de la sociedad civil. En D. Sánchez \& C. Egea (Coords.), La ciudad, un espacio para la vida. Miradas y enfoques desde la experiencia espacial (pp. 124-145). Editorial de la Universidad de Granada.

Vega, P. (2017). La desigualdad invisible: el uso cotidiano de los espacios públicos en la Lima del siglo xxi. Territorios, (36), 23-46. http://dx.doi.org/10.12804/revistas.urosario. edu.co/territorios/a.5097

Velásquez, C. V. \& Meléndez, L. A. (2003). La morfología y los usos de las plazas urbanas y parroquiales de la ciudad de Maracaibo. Opción, 19(40), 69-87. http://ve.scielo.org/ scielo.php?script=sci_arttext\&pid=S1012-15872003000100005\&lng=es\&tlng=esVe rgara, A. (2006). Espacio, lugar y ciudad: etnografía de un parque. En A. Lindón, D. Hiernaux \& M. Á. Aguilar, Lugares e imaginarios en la metrópolis (pp. 149-160). Anthropos. 
Vivas, F. (2006). Patología del espacio público: las calles del barrio obrero en San Cristóbal, Venezuela. Quivera. Revista de Estudios Territoriales, 8(2), 130-150. https://quivera. uaemex.mx/article/view/10537

Vivas, F. (2009). El espacio público como parte del sistema de lugares en tres casos de estudio. FERMENTUM, Revista Venezolana de Sociología y Antropología, 19(54), 11-34. http:// www.saber.ula.ve/handle/123456789/30187 
